\title{
Comparison between Effect of Balloon Blowing Exercise (BBE) in Semi-Fowler (45 Degree), Upright \& 90/90 Bridge with Ball Position on Peak Expiratory Flow Rate in Healthy Individuals
}

\author{
Aditi Sanjay Pawaskar ${ }^{1}$, Richa Bisen ${ }^{2}$ \\ ${ }^{1}$ Former Intern at Smt. Kashibai Navale College of Physiotherapy, Smt. Kashibai Navale College of \\ Physiotherapy, Maharashtra University of Health Sciences, Pune, Maharashtra. \\ ${ }^{2}$ Assistant Professor at Electrotherapy and Electrodiagnosis Department at Smt. Kashibai Navale College of \\ Physiotherapy, Maharashtra University of Health Sciences, Pune, Maharashtra.
}

Corresponding Author: Richa Bisen

\begin{abstract}
Purpose: This study was conducted to investigate the Comparison between effects of balloon blowing exercise (BBE) in Semi Fowlers (45 degree), Upright \& 90/90 Bridge with ball position on Peak expiratory flow rate in healthy individuals.

Participants \& Method: Participants were randomly assigned in respective groups to perform the balloon blowing activity. The exercise programs were conducted 30 minutes per day, 5 times a week for 4 weeks, Peak expiratory flow rate was measured with mechanical equipment called Peak Expiratory Flow Meter before and after the exercise program period.

Results: Effectiveness of Semi fowlers position for Balloon blowing activity is significantly more than that of Upright and 90/90 Bridge Position with Ball on Peak expiratory flow rate pre and post values $(\mathrm{p}<0.005)$

Conclusion: With accordance to objectives, Comparison of Peak expiratory flow rate values in pre \& post exercise in three positions shows that there is improvement of group $\mathrm{A}(\mathrm{Semi}$ fowlers position)> Group C(90/90 Bridge with ball position) $>$ Group B(Upright position)
\end{abstract}

Keywords: Peak expiratory flow rate (PEFR), Balloon blowing exercise (BBE), Semi fowlers position, Upright position, 90/90 Bridge will ball position

\section{INTRODUCTION}

Pulmonary physical therapy has focused largely on improving ventilation. Bronchial drainage techniques have incorporated body positioning to effect gravity-assisted mucous clearance and to enhance air entry ${ }^{1}$. Positions affect respiratory muscle activity by changing the length of the respiratory muscles \& have effect on lung volumes as the body biomechanics change, observed in previous studies that physiological \& scientific rational for use of body positioning as primary intervention in remediating respiratory impairment will maximize physiotherapy efficacy. ${ }^{2,3}$

The purpose of this study is Comparison between effect of Balloon blowing exercise in semi fowlers, upright \& 90/90 bridge position with ball on Peak expiratory flow rate on healthy individuals

The 90/90 bridge with ball position is designed to help restore the Zone of apposition and spine to a proper position in order to allow the diaphragms optimal ability to perform both its respiratory and postural roles in normal individuals. Boyle et.al the balloon-blowing exercise in a bridge position using hip and knee flexion is proposed here as a breathing exercise and preventive method that can be performed daily by patients without professional help. 
The purpose of this study is to apply the present study to the lung function enhancement based on the theory that can improve the contractile motion of the trunk respiratory muscles. Fitness effect of a bridging exercise with a balloon blowing in healthy young adults has not been previously reported. A bridging exercise with a balloon blowing has been studied previously $^{4}$

Jin Seop Kim and Yeon Seop Lee et al. the results show that the pulmonary function of balloon blowing training group were significantly improved compared to those of the non training group, indicating that balloon blowing training had a positive effect on the improvement of the pulmonary functions of young male smoker ${ }^{5,6}$. The experimental group included balloon blowing activity in upright position. Reports have provided evidences about Upright position balloon blowing activity.

Semi Fowler's position is one of the independent interventions that can maximize lung expansion, reduce the abdominal pressure, and provide an effective airway ${ }^{8}$. Semi fowler position is giving a position with a slope of $30-45^{\circ}$ of bed $^{8}$. Semi-fowler position can be given to patients with asthma who experience impaired gas exchange, ineffective airway, and changes in breathing patterns. The goal of this intervention is to reduce $\mathrm{O} 2$ consumption, maximize lung expansion, and provide the patient comfort ${ }^{9}$. No studies have been observed on the Semi-Fowler's position and its effect on PEFR on balloon blowing exercise in healthy individuals.

119 Balloon blowing exercise (BBE) requires greater action of the respiratory muscles as the volume of the balloon increases, because the resistance is increased by the air blown into the balloon. Lee et al. Study reported that balloon blowing increased the maximum expiratory volume. They commented that, in balloonblowing, greater action of the respiratory muscles is required as the volume of the balloon increases, because the resistance is increased by the air blown in into the balloon. As balloon blowing can strengthen the expiratory muscles many studies were made regarding this ${ }^{10}$. BBE is a specific example of an exercise that could be useful for integrating co-activation of deep abdominal muscles with pelvic floor and diaphragm during neuromuscular training and a wide variety of stabilizing maneuvers.

The Balloon Blowing Exercise is a conservative exercise intended to assist a patient/athlete in obtaining optimal posture and respiration i.e. Diaphragm (Zone Of Apposition) and neuro motor control ${ }^{10,11}$.

At higher lung volumes there is greater elastic recoil of the lungs \& chest wall \& expiratory muscle are at a more optimal part of length tension relationship curve $\&$ thus are capable of generating higher expiratory flow

Expiration is a passive process as a result of which the dimension and the force of the thoracic cavity is lowered and it will cause the expelling of air from the lungs. During this activity the coastal are lowered by the intercostals muscles and the diaphragm is raised to resume its original position as the result of this movement and the size of the thoracic cavity is reduced and lungs is higher than the atmospheric pressure and the air rushes out of the nose and trachea this is called forced expiration. Peak Expiratory Flow Rate mainly consider the large airways flow and it relies on the voluntary attempt and muscle power, maximum flow of air occurs during the effort dependent part of the expiration movement, so low expiration rate is caused by the little than the maximal effort rather than the obstruction ${ }^{12}$.

The Peak Expiratory Flow rate is calculated using the Peak expiratory flow meter. Peak Expiratory Flow Meter, is a compact hand held apparatus which shows how speed air comes out of the lung when blow out forcefully after taking gasp of air completely. By this way a person's ability to breathe out can be monitored it is typically measured in units of litres per minute ${ }^{13}$. 
As there is scarcity of studies done on effect of Balloon Blowing Exercise on Peak Exercise Flow Rate value in Upright \& 90/90 bridge position with ball \& there is lack of evidence on effect of Balloon Blowing Exercise on Peak Expiratory Flow Rate value in Semi fowler's position and as change in position affects Peak Expiratory Flow Rate value we would like to study the effect of Balloon Blowing Exercise on Peak Expiratory Flow Rate in the above three positions $\&$ as per the current study results the maximal effective position will be attained.

\section{MATERIALS \& METHODS}

Type of Study design: Comparative study

Location: Narhe, Pune

Duration of study: 4 weeks

Study population: Healthy individuals in the age group 18-25 years.

Method of selection: Convenient sampling.

Inclusion criteria: Healthy individuals in the age group 18-25 years.

Exclusion criteria: CNS dysfunction, Amputation of limbs, Orthopaedic and cardiopulmonary pathology

Outcome measures: Peak expiratory flow rate

Tool: Peak expiratory flow meter

\section{Method of selection of comparison:}

- Ethical clearance from the ethical committee of the institute was obtained.

- Permission from principal of SKNCOPT was taken.

- Subjects were selected according to the inclusion criteria and exclusion criteria.

- Informed and written consent was taken from subjects after explaining the purpose of the study.

- They were further divided into Group A, Group B and Group C by convenient sampling.

- Peak Expiratory Flow Rate was measured in a sitting position using peak expiratory flow meter tool. To ensure accurate measurements, subjects were explained about exercise \& demonstration was given.

- The duration of the training was for 4 weeks, 5 times per week and the program for balloon blowing exercise (BBE) was carried out for $30 \mathrm{~min}$.

- The balloon was changed regularly \& sanitation was maintained with universal precautions.

Write here procedure/technique of your research study.

\section{Statistical Analysis}

Statistically, the results showed significant changes in PEFR with Group C $>$ Group A> Group B

This study showed that the position 90/90 bridge with ball and semi fowlers' position is more effective than upright position and improved the Peak Expiratory Flow Rate of the individual. Whereas the group B didn't show significant improvement as compared to group $\mathrm{A}$ and $\mathrm{C}$

\section{RESULT}

Table 1: Distribution of subject according to age wise

\begin{tabular}{|l|l|}
\hline Domain & Mean \pm SD \\
\hline Age A & $21.933 \pm 1.311$ \\
\hline Age B & $21.967 \pm 1.377$ \\
\hline Age C & $22.500 \pm 1.196$ \\
\hline
\end{tabular}

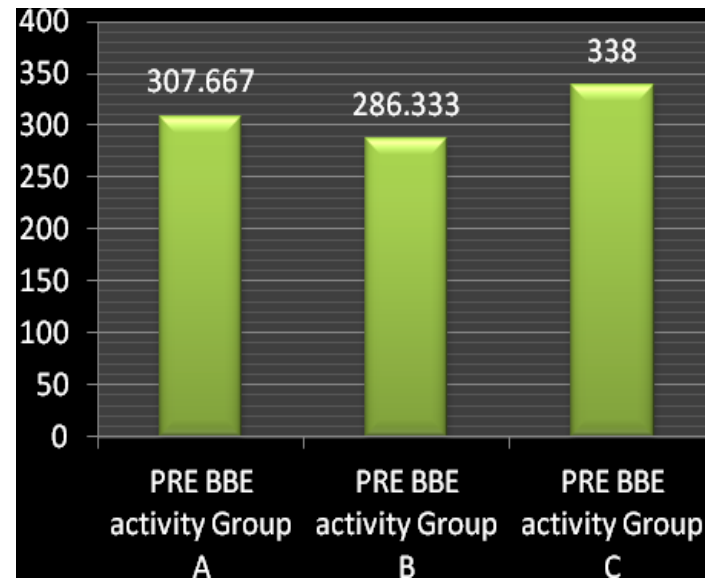

Graph 1: Comparison between Peak Expiratory Flow Rate values pre Balloon Blowing Exercise activity

Observed that the baseline of all the Groups is same 


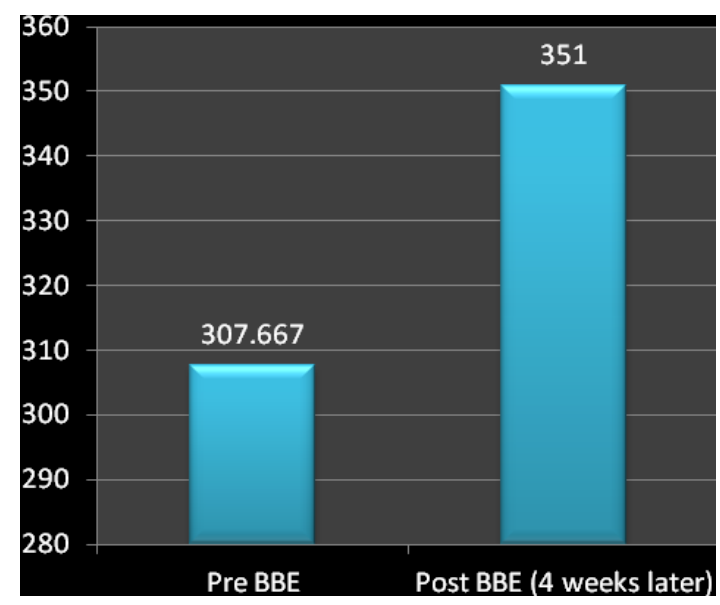

Graph 2: According to pre and post Balloon Blowing Exercise activity in Group A (Semifolwers position)

Comparison of Peak Expiratory Flow Rate values pre and post Balloon Blowing Exercise activity In group A PRE Balloon Blowing Exercise activity mean: $p=0.028$ (highly significant)

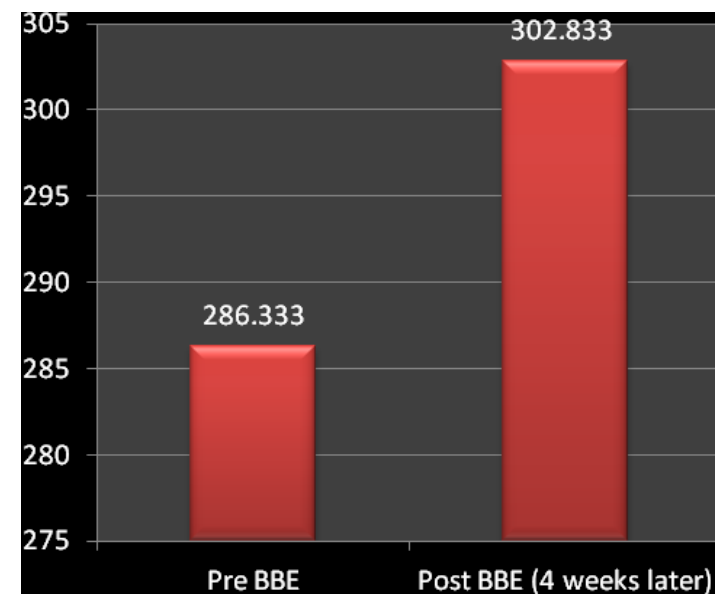

Graph 3: According to pre and post Balloon Blowing Exercise activity in GroupB ( Upright position)

Comparison of PEFR values pre and post BBE activity in group $B$ PRE BBE activity mean : $p=0.501 N S$

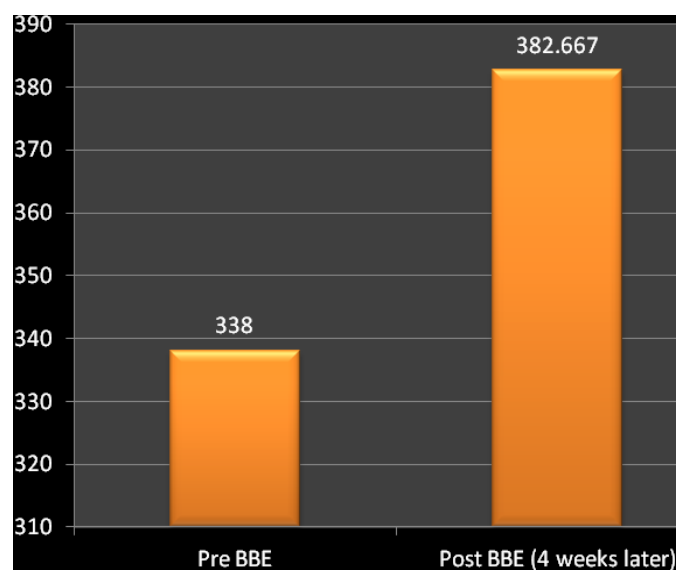

Graph 4: According to pre and post BBE activity in Group C (90/90 bridge position with ball)

Comparison of PEFR values pre and post BBE activity in group $C$ PRE BBE activity mean: $p=0.080$ ( significant)

\section{DISCUSSION}

- This study investigated the effects on PEF on performing a balloon blowing exercise in positions: Semi fowlers, Upright, 90/90 Bridge with ball positions. The purpose of this study was comparison of 3 different positions and choosing the best position giving best results. When the Peak Expiratory Flow Rate was measured on day 1 and compared to the end ${ }^{\text {th }}$ day readings of Peak Expiratory Flow Rate of 4 weeks program, statistically showed the significant changes in Peak Expiratory Flow Rate with group A > group B> group C.

- Study highlighted that the position 90/90 bridge with ball and semi fowlers' position is more effective than upright position and improved the Peak Expiratory Flow Rate of individual. Whereas Group B didn't show significant improvements as compared to group $\mathrm{A}$ and group $\mathrm{C}$. The balloon resistance causes increase in contraction of diaphragm muscle, with is active during forced exhalation. In respiratory cycle with resistance, required lengthening and contraction of both internal and external intercostals, which are active in both phases of respiration.

- There is dearth of literature regarding the effectiveness of semi fowler's position on Peak Expiratory Flow Rate during balloon blowing exercise. This study, semi fowlers position for BBE activity is significantly more than compared to Group B and Group C and its the most comfortable and effortless position that can be easily adapted by patients as compared to Group C position.

- In Group A position the diaphragm moves downward the work of breathing relatively decreases, lung volume and ventilation increases and lung dilatation is promoted, these changes can improve oxygenation and increases oxygen saturation 
- In the current study Group B position effect on balloon blowing exercise on Peak Expiratory Flow Rate showed improvement but not significant changes as compared to Group A and Group C.

- In semi fowlers position the patient is asked to lie down over the bed elevated to 45 degree. Previous studies have showed the improvement of lung oxygenation in this position so we have tried this position in blowing up a balloon that has proved to be significantly useful in improving the Peak Expiratory Flow Rate.

- In upright position there is increase in the values pre and post exercise but not as comparative to the other positions and has proved to be the position where subjects require back rest and many of the cannot sit erect for blowing up a balloon even this position shows positive results but it has low significance as compared with the other positions.

- Since PEFM is a cheap and movable device and it can be used and easily taught to the personnel and staff. It can be given to places where spirometer cannot be used.

- Lee.et.al reported that balloon blowing exercise was helpful for increasing $\mathrm{VC}$, ERV, FEV1/FVC, and PEF. Results of current study relates same to Peak expiratory flow rate ${ }^{5,6}$.

- Jun.et.al reported that the FVC, FEV1/FVC and PEF of elderly smokers were significantly increased by performing balloon blowing exercise or feedback breathing.

- Respiratory exercise with an resistive device such as balloon are found to be effective not only healthy young population but also in population with neurological disease.

- Boyle.et.al by working on zone of apposition in improving lung volume. The position 90/90 bridge with ball position doing balloon blowing activity leads to increase in length of zone of apposition that's the root cause for change in diaphragmatic length alteration of results ${ }^{4}$.

- Study of Jin-Seop Kim and Yeon-Seop the results show that the pulmonary function of balloon blowing training group were significantly improved compared to those of the non training group, indicating that balloon blowing training had a positive effect on the improvement of the pulmonary functions of young male smoker. The experimental group included balloon blowing activity in upright position. This is also supported by our current study $^{7}$.

- Our study is quiet similar to the above studies where there is addition to the dearth of literature the balloon blowing exercise in Semi fowlers position and its effect on Peak Expiratory Flow Rate.

\section{CONCLUSION}

Thus it can be concluded from the present study that the effectiveness of semi fowlers position for Balloon Blowing Exercise activity is significantly more than upright position and similar to 90/90 bridge position with ball on Peak Expiratory Flow Rate pre and post values $(\mathrm{p}<0.05)$.

\section{Acknowledgement: None}

\section{Conflict of Interest: None}

\section{Source of Funding: None}

\section{Ethical Approval: Approved}

\section{REFERENCES}

1. Badr, C, Elkins, MR Ellis, ER. The effect of body position on maximal expiratory pressure and flow. Australian Journal of Physiotherapy, 2002; 48 (2),95- 102

2. Naitoh, S, Tomita, K, Sakai, K, Yamasaki, A, Yuji K, Shimizu, E. Effects of Body Position on Lung Function, Chest Wall Motion, and Discomfort in Healthy Young Participants. Journal of Manipulative and Physiological Therapy. 2014; 37: 9, 719725 
3. Dean, E. (2014). Effect of Body Position on Pulmonary Function. Journal of American Physical Therapy.

4. Boyle KL, Olinick J, Lewis C: The value of blowing up a balloon. N Am J Sports Phys Ther, 2010, 5: 179-188.

5. Lee SC, Jung $\mathrm{CH}$, Lee ES, et al.: Changes of respiratory ability according to respiratory muscle exercises for smokers and non smokers in their twenties. J Kor Phys Ther Sci, 2011, 18: 9-16.

6. Lee SC, Sin SH, Jung JY, et al.: The effects of balloon blow-ups and upper abdominal exercise on respiratory rehabilitation. J Kor Phys Ther Sci, 2011, 18: 17-24

7. Sim SH, Oh DW, Lee GW: The effects of thoracic flexibility exercise on vital capacity and chest expansion in patients with idiopathic scoliosis. Korean Res Soc Phys Ther, 2002, 9: 145-156

8. Manurung Nixson. 2016. Application of Nursing Respiratory System Nursing. Jakarta: Trans Info Medika.

9. Ritianingsih N dan Nurhayati F. 2017. Duration associated with Quality of Life Patients with Chronic Obstructive Pulmonary Disease (COPD). Jurnal Kesehatan Bakti Tunas Husada 17 (1): 133138
10. Lando Y, Boiselle PM, Shade D, et al. Effect of Lung Volume Reduction Surgery of Diaphragm Length in Severe Chronic Obstructive Pulmonary Disease. Am J Respir Crit Care Med. 1999;159(3):796805.

11. Celli B. Clinical and Physiologic Evaluation of Respiratory Muscle Function. Clin Chest Med. 1989;10(2):199-213.

12. Kera T, Kawai H, Hirano H, Kojima M, Fujiwara Y, Ihara K, Obuchi S. Relationships among peak expiratory flow rate, body composition, physical function, and sarcopenia in community-dwelling older adults. Aging Clin Exp Res 2018;30(4):331-40

13. Ma X, Yue ZQ, Gong ZQ, Zhang H, Duan NY, Shi YT, Wei GX, Li YF. The effect of diaphragmatic breathing on attention, negative affect and stress in healthy adults. Front Psychol 2017;8:874.

How to cite this article: Pawaskar AS, Bisen R. Comparison between effect of balloon blowing exercise (BBE) in Semi-Fowler (45 degree), upright \& 90/90 bridge with ball position on peak expiratory flow rate in healthy individuals. International Journal of Research and Review. 2021; 8(8): 214-219. DOI: https://doi.org/10. 52403/ijrr.20210830 